Check for updates

Cite this: Mater. Horiz., 2021, 8,2823

Received 13th March 2021

Accepted 13th August 2021

DOI: $10.1039 / \mathrm{d} 1 \mathrm{mh} 00433 f$

rsc.li/materials-horizons

\section{Aged layered double hydroxide nanosheet- polyvinyl alcohol dispersions for enhanced gas barrier coating performance $\dagger$}

\author{
Jingfang Yu, (DD a Chunping Chen, ${ }^{a}$ James B. Gilchrist, ${ }^{b}$ Jean-Charles Buffet, (DD ${ }^{a}$ \\ Zhonghua Wu, (DD ${ }^{c}$ Guang Mo, ${ }^{c}$ Fei Xie ${ }^{c}$ and Dermot O'Hare (D) *a
}

Whilst applying a coating layer to a polymer film is a routine approach to enhance the gas barrier properties of the film, it is counter-intuitive to consider that the gas barrier performance of the film would improve by ageing the coating dispersion for weeks before application. Herein, we report that the oxygen barrier performance of a $12 \mu \mathrm{m}$ PET film coated with a dispersion of inorganic nanosheets in polyvinyl alcohol can be significantly enhanced by ageing this coating dispersion for up to 8 weeks before application. We found up to a 37-fold decrease in the oxygen transmission rate (OTR) of the PET coated film using aged dispersions of $\left[\mathrm{Mg}_{0.66} \mathrm{Al}_{0.33}(\mathrm{OH})_{2}\right]\left(\mathrm{NO}_{3}\right)_{0.33}$ layered double hydroxide nanosheets ( $\mathrm{Mg}_{2} \mathrm{Al}-\mathrm{LDH} \mathrm{NS}$ ) in polyvinyl alcohol (PVA) compared to the film coated with an equivalent freshly prepared LDH/ PVA dispersion. A limiting OTR value of $0.31 \mathrm{cc} \mathrm{m}^{-2}$ day $^{-1}$ was achieved using the PET film coated with a 3 week aged LDH NS/ PVA dispersion. X-ray diffraction experiments show that the degree of in plane alignment of LDH NS on the PET film surface increased significantly from $70.6 \pm 0.6$ to $86.7 \pm 0.6$ (\%) $(100 \%$ represents complete alignment of LDH NS platelets on the film surface) for the 4 week aged dispersion compared to the freshly prepared layer. We postulate that when the $\mathrm{Mg}_{2} \mathrm{Al}-\mathrm{LDH} \mathrm{NS}$ are aged in PVA the coiled PVA aggregates start to unwrap and attach onto the $\mathrm{Mg}_{2} \mathrm{Al}$-LDH NS through hydrogen bonding and eventually form a hydrogen bonded ordered network that facilitates the alignment of nanosheet dispersions during the coating process. Our results suggest that the ageing of inorganic nanosheet dispersions in PVA or other potential hydrogen bonding adhesive systems could be a general approach to improve the alignment of the nanosheets on the polymer film surface once applied and thus improve their performance characteristics for barrier coating applications.

\section{New concepts}

Our work describes the first demonstration that application of an aged dispersion of inorganic nanoplatelets in an adhesive to a polymer film significantly increases the oxygen barrier performance. We discovered that upon ageing a dispersion of layered double hydroxide nanosheets (LDH NS) and polyvinyl alcohol (PVA) in water, a weakly hydrogen bonded network connecting the LDH particles with the PVA chains formed. This network facilitates the alignment of LDH NS on the surface of the polymer film during the coating process. The oxygen transmission rate of a coated PET film exhibited a 37 -fold decrease using an 8 week aged LDH/PVA dispersion compared to the film coated with an equivalent freshly prepared LDH/PVA dispersion. We observe an improved degree of inplane alignment of LDH NS on the PET substrate surface. We suggest that ageing of inorganic nanosheet dispersions in PVA or other potential hydrogen bonding adhesive systems could be a general approach to improve the barrier performance of coated polymeric films.

\section{Introduction}

Hydrogen bonding is one of the most common examples of a dynamic linkage; it enables the construction of functional supramolecular polymers, ${ }^{1}$ dominates the interactions within a polymer nanocomposite, ${ }^{2,3}$ and stabilises biological macromolecules. ${ }^{4}$ It is widely exploited in adhesive coatings, ${ }^{5,6}$ self-healing hydrogels, ${ }^{7,8}$ stimuli responsive polymers, ${ }^{9}$ and drug discovery. ${ }^{10-12}$ It has been established that such a weak interaction enhances the mechanical properties of a polymer composite and enables selfhealing due to the ability to reform hydrogen bonds at interfaces. However, hydrogen bonding has rarely been recognised to promote the gas barrier properties of a coated film.

Gas barrier coated film is a common packaging material used to protect moisture or gas-sensitive products such as

\footnotetext{
${ }^{a}$ Chemistry Research Laboratory, Department of Chemistry, University of Oxford, 12 Mansfield Road, Oxford, OX1 3TA, UK.

E-mail: dermot.ohare@chem.ox.ac.uk; Tel: +44(0)1865 272686

${ }^{b}$ eBIC, Diamond Light Source, Oxfordshire, OX11 ODE, UK

${ }^{c}$ Beijing Synchrotron Radiation Facility, Institute of High Energy Physics, Chinese Academy of Sciences, Beijing, 100049, P. R. China

$\dagger$ Electronic supplementary information (ESI) available. See DOI: 10.1039/d1mh00433f
} 
electronics, foods, and medical supplies from deterioration. Aluminium (metallised) film is the current industry standard to achieve a high gas barrier packaging material. However, due to difficulties in recycling and pollution, recyclable and eventually biodegradable gas barrier packaging materials that meet future requirements must be developed. For example, the flexible electronics industry requires a water vapour transmission rate $^{13}$ at the order of $10^{-3}$ to $10^{-6} \mathrm{~g} \mathrm{~m}^{-2}$ day $^{-1}$ and the food industry requires an oxygen transmission rate at the order of $10^{-1} \mathrm{cc} \mathrm{m}^{-2}$ day $^{-1}$. A well-recognised approach to improve the gas barrier properties of a polymeric film is to introduce a longer gas diffusion pathway, namely a tortuous pathway, ${ }^{14,15}$ by aligning inorganic nanosheets. Previous studies have shown that inorganic platelet samples such as MMT, ${ }^{15,16}$ LAPONITE $^{\circledR},{ }^{17}$ graphene oxide ${ }^{18,19}$ as well as layered double hydroxides $(\mathrm{LDH})^{20,21}$ can significantly enhance oxygen barrier performance once aligned in a polymeric film surface. Much effort has been invested into both the design of an efficient alignment method such as the layer-by-layer method ${ }^{22,23}$ or tailoring the aspect ratio of the impervious inorganic filler. ${ }^{16,22}$ However, hydrogen bonding has rarely been recognised as a credible approach to improve the alignment of nanosheets on a polymer film substrate.

Herein, we report that the oxygen barrier performance of polyethylene terephthalate (PET) films can be significantly enhanced by applying a coating layer comprised of an aqueous dispersion of layered double hydroxide nanosheets $\left(\left[\mathrm{Mg}_{0.66}{ }^{-}\right.\right.$ $\left.\left.\mathrm{Al}_{0.33}(\mathrm{OH})_{2}\right]\left(\mathrm{NO}_{3}\right)_{0.33} ; \mathrm{Mg}_{2} \mathrm{Al}-\mathrm{LDH} \mathrm{NS}\right)$ and polyvinyl alcohol (PVA) that has been aged for 5-6 weeks. In fact, the oxygen transmission rate (OTR) of a $12 \mu \mathrm{m}$ PET film coated with a layer consisting of PVA $\left(M_{\mathrm{w}}\right.$ of $\left.67000 \mathrm{~g} \mathrm{~mol}^{-1}\right)$ and the $\mathrm{Mg}_{2} \mathrm{Al}-\mathrm{LDH} \mathrm{NS}$ decreases as the ageing time of the aqueous $\mathrm{Mg}_{2} \mathrm{Al}-\mathrm{LDH}$ NS/PVA dispersion increased (Scheme 1). Remarkably, the OTR (tested at $0 \% \mathrm{RH}$ and $23{ }^{\circ} \mathrm{C}$ ) of the coated PET film displayed a $c a$. 60 -fold decrease by simply ageing the coating dispersion for 6 weeks. Structural characterisation of a freshly coated film compared to one prepared with the same coating 4 weeks later showed that the degree of in-plane alignment of LDH NS on the coating layer increased significantly from $70.6 \pm 0.6$ to $86.7 \pm 0.6(\%)$, which according to conventional torturous path theory will directly contribute to the gas barrier enhancement. IR experiments suggest that hydrogen bonding interactions form between the hydroxyl groups of the PVA and surface formamide groups ( $-\mathrm{COOH}$ and $-\mathrm{NH}_{2}$ groups) on the $\mathrm{Mg}_{2} \mathrm{Al}-\mathrm{LDH}$ platelets when the coating dispersion is aged. We postulate that when the $\mathrm{Mg}_{2} \mathrm{Al}-\mathrm{LDH}$ NS are aged in PVA the coiled PVA aggregates start to unwrap and attach to the $\mathrm{Mg}_{2} \mathrm{Al}-\mathrm{LDH}$ NS through hydrogen bonding (phase II) and eventually form a hydrogen bonded network (phase III) that facilitates the alignment of nanosheet dispersions during the coating process (Scheme 1). We have also observed the same ageing effect in glycine containing LDH NS and in other inorganic nanosheet dispersions such as bentonite dispersed in PVA. Our results indicate that the formation of a hydrogen bonded network by ageing the coating dispersion could be a general strategy to enhance the gas barrier performance of inorganic nanosheets dispersed on a polymer film.

\section{Results and discussion}

\section{Preparation of $\mathrm{Mg}_{2} \mathrm{Al}-\mathrm{LDH}$ nanosheets}

A previously reported method was modified to prepare the $\left[\mathrm{Mg}_{0.66} \mathrm{Al}_{0.33}(\mathrm{OH})_{2}\right]\left(\mathrm{NO}_{3}\right)_{0.33}$ nanosheet dispersion $\left(\mathrm{Mg}_{2} \mathrm{Al}-\mathrm{LDH}\right.$ NS) in 30 vol\% aqueous formamide ${ }^{23}$ (ESI $\dagger$ ). The $\mathrm{Mg}_{2} \mathrm{Al}-\mathrm{LDH}$ NS (Fig. 1a inset) displayed an interlayer separation of $7.9 \AA$ (Fig. 1a) consistent with the interlayer space being occupied by nitrate anions. ${ }^{23,24}$ TEM imaging shows the nanosheets have a

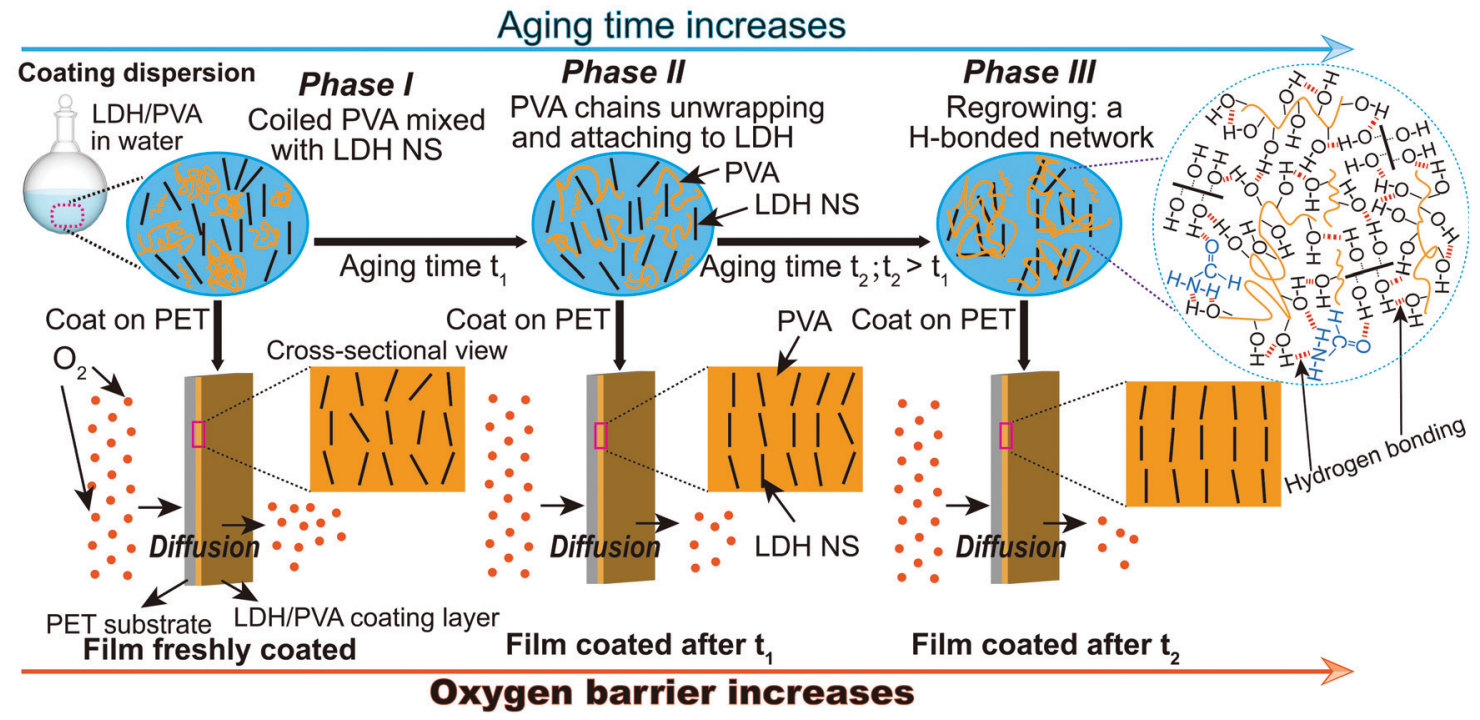

Scheme 1 Schematic of the ageing process. The oxygen barrier performance of a barrier film increases significantly when the coating dispersion was aged due to the formation of a hydrogen bonded network over time. Proposed three stages of the dispersion ageing process: (I) coiled PVA mixed with LDH NS; (II) PVA chains start to unwrap and attach to the LDH NS surface through hydrogen bonding; (III) PVA chains wrapped around the LDH NS to connect individual NS and form a hydrogen bonded network. 

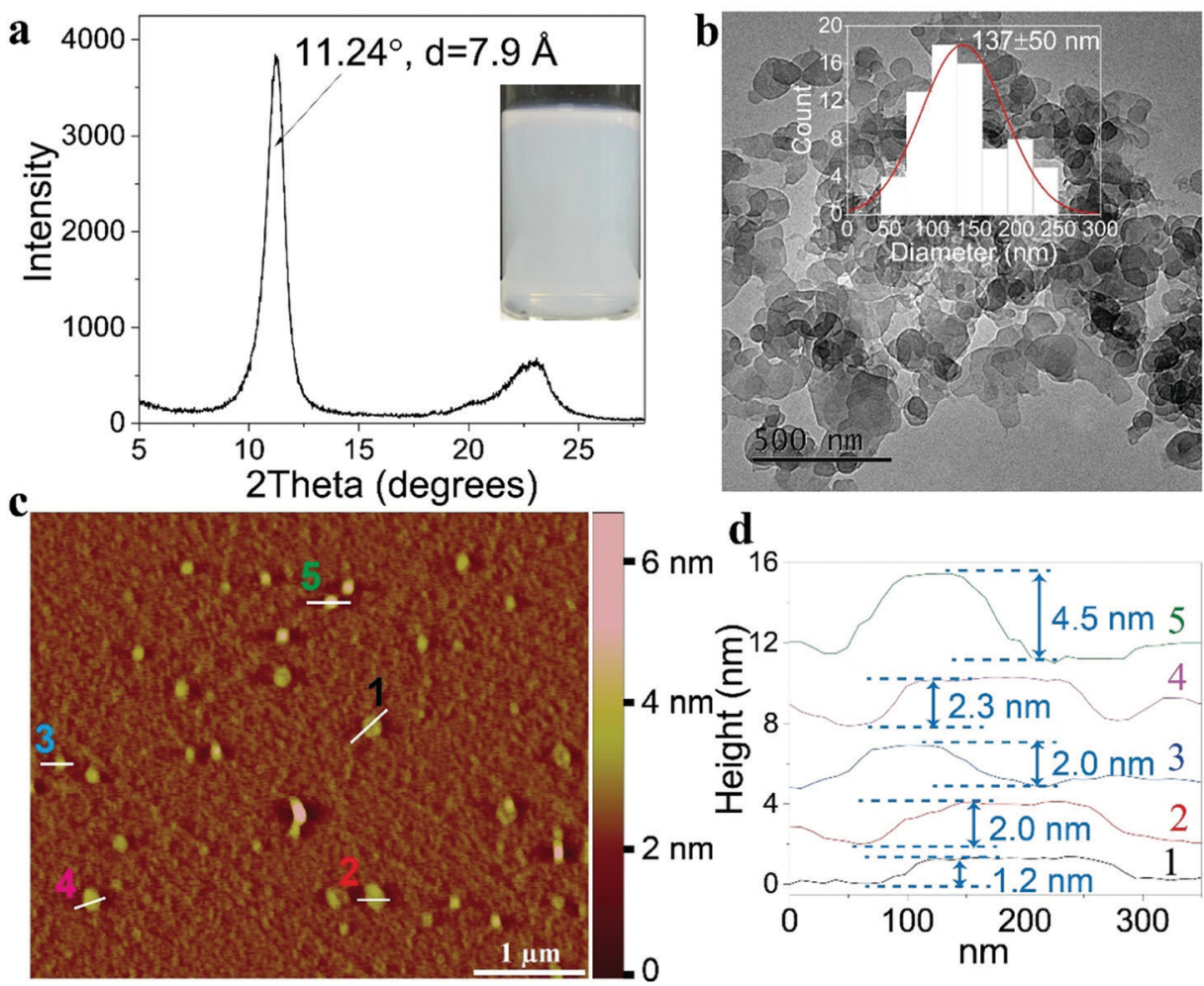

d

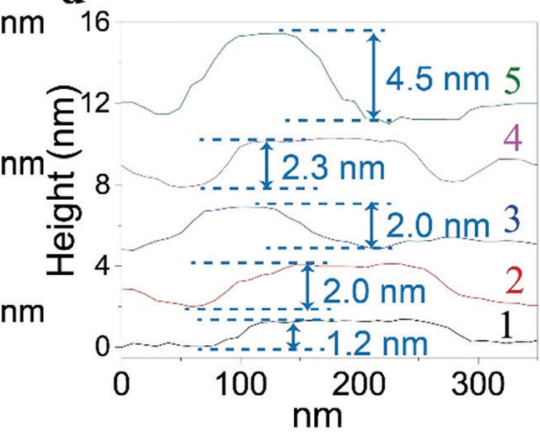

Fig. 1 Characterisation of the $\mathrm{Mg}_{2} \mathrm{Al}-\mathrm{LDH}$ nanosheets. (a) XRD pattern of freshly prepared $\mathrm{Mg}_{2} \mathrm{Al}-\mathrm{LDH}$ nanosheets and their dispersion in water (inset). (b) TEM image of the nanosheets and the inset shows the diameter histogram. AFM image (c) and the corresponding height profile (d) of LDH particles 1-5.

mean platelet diameter of $c a .137 \pm 50 \mathrm{~nm}$ (Fig. 1b) and atomic force microscopy (AFM) measurements (Fig. 1c and d and Fig. S1, ESI $\dagger$ ) show a mean diameter of $208 \pm 52 \mathrm{~nm}$ (Fig. S1a, ESI $\dagger$ ). Thus, the diameter of the nanosheet sample is $<200 \mathrm{~nm}$. AFM measurements indicated that the nanosheets are very thin platelets with a mean thickness of $c a .1 .9 \pm 0.9 \mathrm{~nm}$ (Fig. 1c and d, Fig. S1b, ESI $\dagger$ ). The mean aspect ratio (platelet diameter divided by thickness) of the freshly prepared LDH platelets was $118 \pm 52$ (Fig. S1c, ESI†).

\section{Synthesis of gas barrier films}

The $\mathrm{Mg}_{2} \mathrm{Al}-\mathrm{LDH}$ nanosheets were collected by centrifugation to give a gel-like sample, the solid content of the gel was determined by drying in oven at $100{ }^{\circ} \mathrm{C}$ overnight. To prepare a coating dispersion, an appropriate amount of $\mathrm{Mg}_{2} \mathrm{Al}-\mathrm{LDH}$ NS was mixed with a $10 \mathrm{wt} \%$ PVA $\left(M_{\mathrm{w}} 67000 \mathrm{~g} \mathrm{~mol}^{-1}\right)$ stock solution. The coating dispersion was diluted with water to give the desired total solid content. Typically, the coating dispersion contained $X$ wt $\%$ LDH and $Y$ wt $\%$ PVA and $(100-X-Y)$ wt $\%$ water. Thus, the coating dispersion and the correspondingly coated films are labelled $X \mathrm{~L} Y \mathrm{P}$ where $X$ refers to the solid content of LDH and $Y$ refers to the solid content of PVA. After each coating procedure, the dispersion samples were carefully sealed and left to age for specific times. When the $12 \mu \mathrm{m}$ PET film was coated with a freshly prepared coating dispersion, this film is labelled F. When the PET substrate was coated with a coating dispersion sample aged for a duration of time, for example $N$ days, or $M$ weeks, the film is referred to as $N \mathrm{D}$ or
$M$ WK. For example, 6L4P-4WK refers to a film coated with a dispersion containing $6 \mathrm{wt} \% \mathrm{LDH}$ and $4 \mathrm{wt} \%$ PVA (and $90 \mathrm{wt} \%$ water) that was aged for 4 weeks before coating.

A $12 \mu \mathrm{m}$ PET substrate film was coated using a bar coating method $^{21}$ where a coating rod giving a $6 \mu \mathrm{m}$ wet coating layer thickness was used to coat all the films discussed in this paper. The dried coated films are transparent and their transparency is similar to the uncoated PET substrate (Fig. 2a). We have measured the transmittance of film samples coated with 0.6L1.6P and 6L4P dispersion samples (Fig. S2, ESI $\dagger$ ). The transmittance of PET films coated with a freshly prepared 6L4P dispersion is $85.7 \%$. The transmittance of the coated PET film stayed similar at $85.7 \%$ when the same $6 \mathrm{~L} 4 \mathrm{P}$ coating dispersion was aged for 1 week before application. The transmittance of the coated PET film increased to 86.0 and $86.8 \%$ when the same 6L4P coating dispersion was aged for 2 and 3 weeks, respectively, before coating onto the PET substrate. Similarly, the transmittance of the PET film coated with a freshly prepared $0.6 \mathrm{~L} 1.6 \mathrm{P}$ dispersion is $80.3 \%$. The transmittance of the coated PET film increased to 81.3 and $83.5 \%$ when the same 0.6L1.6P coating dispersion was aged for 2 and 6 weeks, respectively, before coating onto the PET substrate. AFM experiments were performed (Fig. S3, ESI $\dagger$ ) to measure the thickness of the coating layers: $89 \pm 18,122 \pm 37$, and $272 \pm$ $56 \mathrm{~nm}$ for the freshly coated 0.6L1.6P, 1.6L0.6P, and 6L4P films, respectively (Fig. 2b). A $12 \mu \mathrm{m}$ PET substrate film was intentionally coated four times with a freshly prepared 1.6L0.6P LDH/PVA dispersion to show the cross-sectional area (the thickness of the 

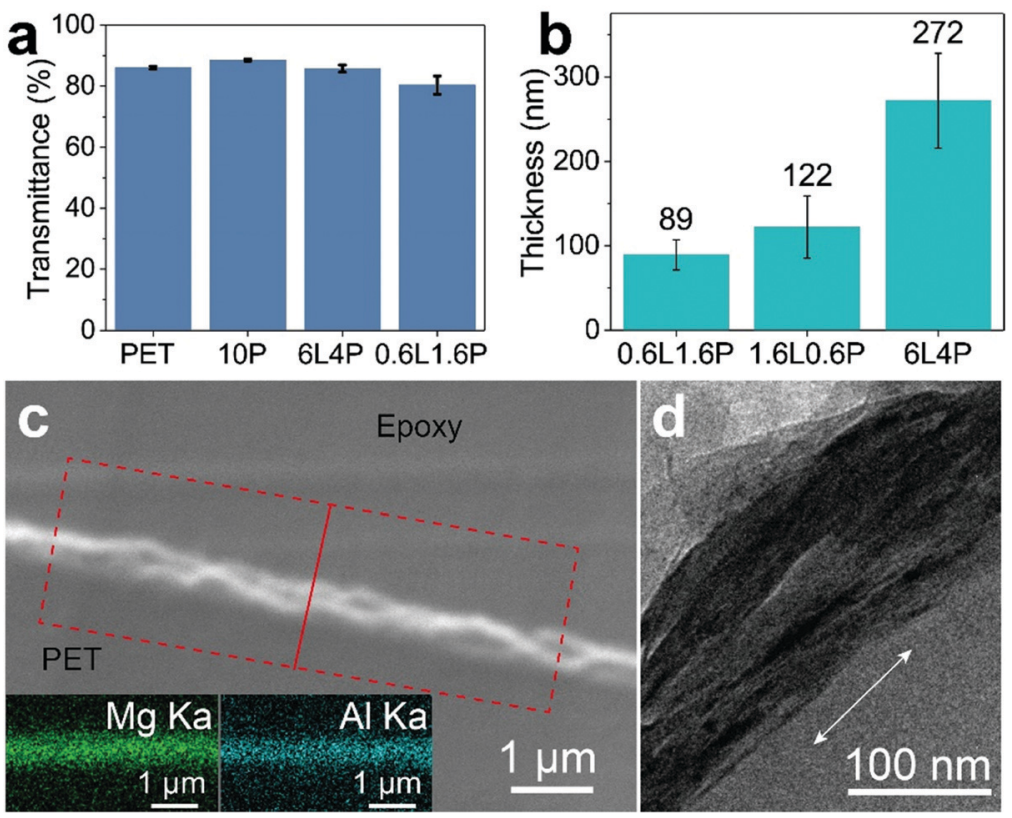

Fig. 2 Film characterisation. (a) Transparency of the gas barrier films for the PET substrate and its freshly coated films (measured at a wavelength of $500 \mathrm{~nm}$ ). (b) Dry coating layer thickness of the films coated with freshly prepared 0.6L1.6P, 1.6L0.6P, and 6L4P coating dispersions measured using AFM. (c) Cross-sectional secondary electron SEM image and the corresponding EDX elemental map in the coating layer. The PET film was coated four times with a freshly prepared 1.6L0.6P LDH/PVA dispersion. (d) Cross-sectional TEM image of the LDH/PVA coating on the PET film (6L4P).

four-time coated film corresponds roughly to four times the thickness of the one-time coated film measured using AFM). The cross-sectional SEM images and EDX mapping (Fig. 2c) confirm the presence of $\mathrm{Mg}$ and $\mathrm{Al}$ in the 1.6L $0.6 \mathrm{P}$ film. The cross-sectional TEM (Fig. 2d) images reveal that the LDH nanosheets are aligned in the coating layer to provide a tortuous pathway.

\section{Ageing effect of the LDH/PVA dispersion on the oxygen barrier performance of PET films}

A pristine $12 \mu \mathrm{m}$ PET film $^{22}$ has an baseline OTR of $133.50 \mathrm{cc} \mathrm{m}^{-2}$ day $^{-1}$ and the OTR decreases to $126.00 \mathrm{cc} \mathrm{m}^{-2}$ day $^{-1}$ when coated with a dispersion containing $6 \mathrm{wt} \%$ LDH NS (Fig. S4, ESI $\dagger$ ). The OTR of a PET film freshly coated with $10 \mathrm{wt} \%$ PVA (10P) is $10.45 \mathrm{cc} \mathrm{m}^{-2} \mathrm{day}^{-1}$. On replacing $6 \mathrm{wt} \%$ of the PVA with $\mathrm{Mg}_{2} \mathrm{Al}-\mathrm{LDH}$ NS (6L4P), the OTR of a freshly coated PET film decreased to $3.00 \mathrm{cc} \mathrm{m}^{-2}$ day $^{-1}$ (Fig. 3a). Surprisingly, we observed that the OTR of the LDH/PVA coated PET decreased when an aged coating dispersion was used. In fact, the OTR of the PET film decreased to $1.80,0.32$, and $0.31 \mathrm{cc} \mathrm{m}^{-2}$ day $^{-1}$ when the same 6L4P coating dispersion was aged for 1,2 and 3 weeks, respectively, before coating onto the PET substrate. In contrast, the OTR increased from 10.45 to $15.40 \mathrm{cc} \mathrm{m}^{-2}$ day $^{-1}$ when the PET substrate was coated with the control solution containing no $\mathrm{Mg}_{2} \mathrm{Al}-\mathrm{LDH}$ NS but just a $10 \mathrm{wt} \%$ PVA solution aged for 1 week. The OTR values of the PET remained at 16.15 and $15.05 \mathrm{cc} \mathrm{m}^{-2}$ day $^{-1}$ when the control 10P solution was aged for 2 and 3 weeks, respectively, before coating. A similar effect was also found with a different LDH/PVA dispersion containing a lower total solid content of $2.2 \mathrm{wt} \%$ (Fig. 3b). The PET substrate freshly coated with a pure $2.2 \mathrm{wt} \%$ PVA (2.2P) solution has an
OTR of $31.50 \mathrm{cc} \mathrm{m}^{-2}$ day $^{-1}$ (Fig. S5, ESI $\dagger$ ). The OTR of the 2.2P solution coated PET films remained similar at 35.00 and $33.30 \mathrm{cc} \mathrm{m}^{-2}$ day $^{-1}$ when the PVA solution was aged for 2 and 4 weeks, respectively. The OTR increased to $59.15 \mathrm{cc} \mathrm{m}^{-2}$ day $^{-1}$ when the 2.2P solution was aged for 6 weeks, probably due to partial decomposition of the polymer. ${ }^{25}$ In contrast, the PET film freshly coated with $1.6 \mathrm{wt} \% \mathrm{LDH}$ NS and $0.6 \mathrm{wt} \%$ PVA (1.6L0.6P) dispersions (total solid content is $2.2 \mathrm{wt} \%$ ) has an OTR of around $20 \mathrm{cc} \mathrm{m}^{-2}$ day $^{-1}$ (the OTR values are 22.65 and $24.10 \mathrm{cc} \mathrm{m}^{-2}$ day $^{-1}$ for the two separately prepared films coated with freshly prepared dispersions aged at $40{ }^{\circ} \mathrm{C}$ for a week before ageing at room temperature and ageing at room temperature continuously) (Fig. 3b). Remarkably, the OTR of a PET film decreased to $12.35 \mathrm{cc} \mathrm{m}^{-2}$ day $^{-1}$ and then to $5.19 \mathrm{cc} \mathrm{m}^{-2}$ day $^{-1}$ when coated with a 1.6L0.6P dispersion after ageing for 2 days and then 4 weeks, respectively (ageing at $40{ }^{\circ} \mathrm{C}$ for a week before ageing at room temperature, Fig. $3 \mathrm{~b}$ in orange). Similarly, the OTR of a PET film decreased to $18.10 \mathrm{cc} \mathrm{m}^{-2}$ day $^{-1}$ and then to $5.81 \mathrm{cc} \mathrm{m}^{-2}$ day $^{-1}$ when coated with a 1.6L0.6P dispersion after ageing for 2 days and 4 weeks (aged at room temperature continuously, Fig. $3 \mathrm{~b}$ in violet).

We further studied the effect of temperature on the ageing of the coating dispersion. Two coating dispersions containing the same composition of $0.6 \mathrm{wt} \%$ LDH NS mixed with $1.6 \mathrm{wt} \%$ PVA (0.6L1.6P) were prepared but aged under different conditions. One was stirred and heated at $40{ }^{\circ} \mathrm{C}$ for a week before ageing at room temperature and the other was aged at room temperature continuously. The OTR of the PET substrate film coated with the freshly prepared $0.6 \mathrm{~L} 1.6 \mathrm{P}$ dispersion (aged at $40{ }^{\circ} \mathrm{C}$ for a week before ageing at room temperature) (Fig. $3 \mathrm{c}$ in blue) is $27.60 \mathrm{cc} \mathrm{m}^{-2}$ day $^{-1}$. When coating the PET substrate with a 

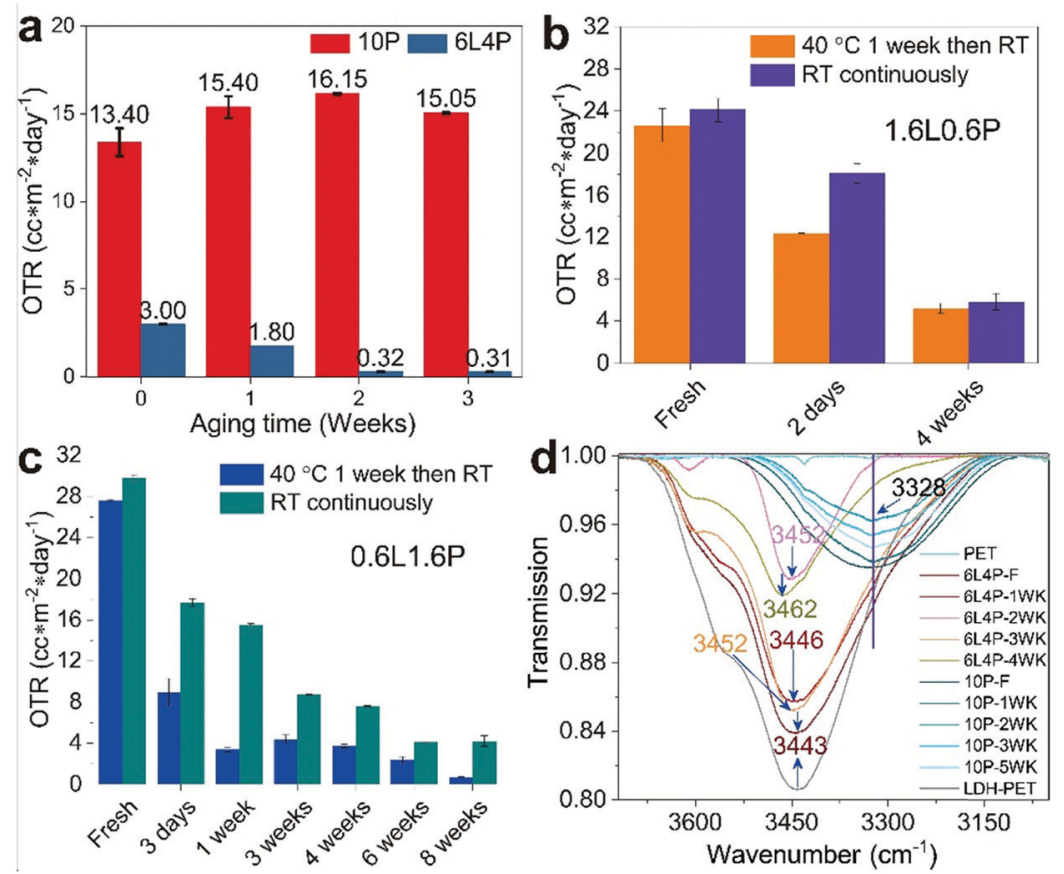

Fig. 3 Ageing effect on the oxygen barrier performance of coated PET films. (a) OTR of PET films coated with freshly prepared and aged 10P and 6L4P $\mathrm{Mg}_{2} \mathrm{Al}-\mathrm{LDH}$ NS/PVA dispersions. (b) OTR of PET films coated with freshly prepared and aged 1.6L0.6P Mg $\mathrm{Al}-\mathrm{LDH}$ NS/PVA dispersions aged at $40{ }^{\circ} \mathrm{C}$ for a week before ageing at room temperature (orange) and at room temperature continuously (violet). (c) OTR of PET films coated with freshly prepared and $0.6 \mathrm{~L} 1.6 \mathrm{P} \mathrm{Mg} 2 \mathrm{Al}-\mathrm{LDH}$ NS/PVA dispersions aged at $40{ }^{\circ} \mathrm{C}$ for a week before ageing at room temperature (blue) and at room temperature continuously (dark cyan). (d) IR-ATR spectra of PET films coated with freshly prepared and aged 6L4P Mg $2 \mathrm{Al}-\mathrm{LDH}$ NS/PVA dispersions, a pure 10 wt\% PVA solution, and a pure 6 wt\% LDH dispersion (resolution is $0.5 \mathrm{~cm}^{-1}$ ). All the films were conditioned at $60{ }^{\circ} \mathrm{C}$ for 2 days to exclude moisture interference before the experiments. All the prepared films were coated with a coating rod with a $6 \mu \mathrm{m}$ coating gap.

3-day-old 0.6L1.6P solution aged at $40{ }^{\circ} \mathrm{C}$, the OTR of the coated film was found to decrease to $8.96 \mathrm{cc} \mathrm{m}^{-2}$ day $^{-1}$. The OTR of the coated film further decreased to $3.36 \mathrm{cc} \mathrm{m}^{-2}$ day $^{-1}$ when the same 0.6L1.6P dispersion was aged at $40{ }^{\circ} \mathrm{C}$ for 1 week. The OTR values of coated PET were 4.38 and $3.74 \mathrm{cc} \mathrm{m}^{-2}$ day $^{-1}$ when the $0.6 \mathrm{~L} 1.6 \mathrm{P}$ dispersion was cooled down to room temperature and then aged for another 2 to 3 weeks (the 3rd and 4th week), respectively. This may be attributed to changes in the PVA associated with temperature fluctuations ${ }^{26,27}$ and a less uniform dispersion as the continuous stirring was stopped. The OTR values of PET coated with an $0.6 \mathrm{~L} 1.6 \mathrm{P}$ dispersion aged for an additional 5 and 7 weeks ( 6 and 8 weeks in total) at room temperature were 2.33 , and $0.74 \mathrm{cc} \mathrm{m}^{-2}$ day $^{-1}$, respectively. This represents a 37 -fold enhancement in the oxygen barrier (decrease in OTR) by simply allowing the coating dispersion to age before application.

Similarly, the $\mathrm{O}_{2}$ transmission rate of the film coated with the 0.6L1.6P dispersion aged continuously at room temperature (Fig. 3c in dark cyan) decreased rapidly when the dispersion was aged compared with the OTR value of the freshly coated film (29.75 $\mathrm{cc} \mathrm{m}^{-2}$ day $\left.^{-1}\right)$. For example, the OTR of the coated film is 17.70 and $15.55 \mathrm{cc} \mathrm{m}^{-2}$ day $^{-1}$ when the $0.6 \mathrm{~L} 1.6 \mathrm{P}$ dispersion is aged for 3 days and a week at room temperature, respectively (Fig. 3c in dark cyan). The OTR of the coated film decreased to 8.72 and $7.60 \mathrm{cc} \mathrm{m}^{-2}$ day $^{-1}$ when the $0.6 \mathrm{~L} 1.6 \mathrm{P}$ dispersion is further aged at room temperature for 3 to 4 weeks, respectively. The OTR of the coated film further decreased to
$4.09 \mathrm{cc} \mathrm{m}^{-2}$ day $^{-1}$ at the 6 th week of ageing and then increased to $4.19 \mathrm{cc} \mathrm{m}^{-2}$ day $^{-1}$ when the dispersion is aged for 8 weeks. This represents only ca. 7-fold decrease in OTR, which is in sharp contrast with the 37-fold decrease in OTR observed in the dispersion containing the same composition of LDH and PVA (0.6L1.6P) but aged under different conditions (aged at $40{ }^{\circ} \mathrm{C}$ under stirring for a week before ageing at room temperature), indicating that raising the ageing temperature to $40{ }^{\circ} \mathrm{C}$ whilst stirring has a significant effect on the ultimate oxygen barrier performance of the coated PET films. It might be that when the $\mathrm{Mg}_{2} \mathrm{Al}-\mathrm{LDH}$ NS are aged in PVA at a higher temperature under stirring, the unwrapping of coiled PVA aggregates and the mixing of LDH and PVA are facilitated, which together leads to a rapidly growing hydrogen bonded network that promotes the alignment of nanosheet dispersions during the coating process (Scheme 1).

The effect of ageing the aqueous dispersion of the pure $\mathrm{Mg}_{2} \mathrm{Al}-\mathrm{LDH} \mathrm{NS}$ on the oxygen barrier was also investigated. The $\mathrm{Mg}_{2} \mathrm{Al}-\mathrm{LDH}$ NS were aged in water for 7 weeks before being mixed with PVA to prepare a coating dispersion containing $1.6 \mathrm{wt} \% \mathrm{LDH}$ and $0.6 \mathrm{wt} \%$ PVA [1.6L(Aged)0.6P]. The freshly coated PET film exhibited an OTR of $50.7 \mathrm{cc} \mathrm{m}^{-2}$ day $^{-1}$ (Fig. S6, ESI $\dagger$ ), much higher than that of the PET film freshly coated with the 1.6L0.6P without ageing the $\mathrm{Mg}_{2} \mathrm{Al}-\mathrm{LDH}$ NS (Fig. 3c). Upon ageing the $1.6 \mathrm{~L}$ (Aged)0.6P dispersion for 1 week, the OTR of the coated film decreases to $7.72 \mathrm{cc} \mathrm{m}^{-2}$ day $^{-1}$, whereas on extending the ageing time to 2 weeks, the OTR of the coated 
film slightly increases to $12.4 \mathrm{cc} \mathrm{m}^{-2}$ day $^{-1}$. The OTR of the coated film stabilises with a small increase to $13.25 \mathrm{cc} \mathrm{m}^{-2}$ day $^{-1}$ (within error) when the coating dispersion is aged for 5 weeks. To explain this phenomenon, AFM measurements were carried out to monitor the aspect ratio (Fig. S7a, ESI $\dagger$ ) of the LDH NS aqueous dispersion aged (10 wt\% solid content) for 6.5 (Fig. S8a, ESI $\dagger$ ), 8.5 (Fig. S9a, ESI $\dagger$ ), and 9.5 months (Fig. S10a, ESI $\dagger$ ), respectively. The mean diameter (Fig. S7b, ESI $\dagger$ ) as well as the mean thickness (Fig. S7c, ESI $\dagger$ ) of the LDH NS sample increased as the LDH NS sample is aged in water. For example, the mean diameter of the freshly prepared LDH NS sample was $208 \pm$ $52 \mathrm{~nm}$ and the value increased to $285 \pm 92 \mathrm{~nm}$ after 6.5 months of ageing (Fig. S8b, ESI $\dagger$ ) further increasing to $281 \pm 105$ and $339 \pm 53 \mathrm{~nm}$ for 8.5 (Fig. S9b, ESI $\dagger$ ) and 9.5 months (Fig. S10b, ESI $\dagger$ ), respectively. Similarly, the mean thickness of the LDH NS sample increased from $1.9 \pm 0.9$ to $12.8 \pm 5.0 \mathrm{~nm}$ after being aged in water for 6.5 months (Fig. S8c, ESI $\dagger$ ) and stabilised at $12.6 \pm 3.2 \mathrm{~nm}$ after being aged for 8.5 months (Fig. S9c, ESI $\dagger$ ). The mean thickness further increased to $17.6 \pm 3.1 \mathrm{~nm}$ after the LDH NS was aged in water for 9.5 months (Fig. S10c, ESI $\dagger$ ). As a result, the mean aspect ratio (Fig. S1d, ESI $\dagger$ ) of the freshly prepared LDH NS sample decreased with ageing time due to the rapid increase of the mean thickness. The mean aspect ratio decreased from $118 \pm 52$ to $24 \pm 11$ when the sample was aged for 6.5 months (Fig. S8d, ESI $\dagger$ ). The mean aspect ratio further decreased to $22 \pm 7$ and $20 \pm 5$ when the ageing time was 8.5 (Fig. S9d, ESI $\dagger$ ) and 9.5 months (Fig. S10d, ESI $\dagger$ ), respectively. Previous results ${ }^{14,15,22}$ have concluded that the relative permeability of a polymeric composite decreases as the mean aspect ratio of a platelet-like sample increases. The OTR of the PET film coated with $1.6 \mathrm{~L}$ (aged)0.6P increased significantly compared with that of the OTR of the film coated with 1.6L0.6P (without ageing the LDH NS), due to the aspect ratio decrease after ageing the LDH NS sample in water. This indicates that the positive processes of ageing the $\mathrm{Mg}_{2} \mathrm{Al}-\mathrm{LDH}$ NS in the presence of PVA are connected with the ageing of the $\mathrm{Mg}_{2} \mathrm{Al}-\mathrm{LDH} \mathrm{NS}$ in water. We believe that ageing the $\mathrm{Mg}_{2} \mathrm{Al}-\mathrm{LDH}$ NS in PVA allows additional short-range ordering to develop through hydrogen bonding interactions between the $\mathrm{Mg}_{2} \mathrm{Al}-\mathrm{LDH}$ NS and the PVA.

We measured the aspect ratio of the LDHs in the 5 week aged 0.6L1.6P coating dispersion to confirm the growth trend. The AFM measurements of individual LDH particles (Fig. S11a, $\mathrm{ESI} \dagger)$ show that the mean aspect ratio of the $\mathrm{LDH}$ particles from 5 week aged $0.6 \mathrm{~L} 1.6 \mathrm{P}$ coating dispersion is ca. $62 \pm 33$ (Fig. S11b, ESI $\dagger$ ), lower than that of the LDH particles $(118 \pm 52)$ from the freshly prepared sample. This is a result of the growth of the LDH in the PVA aqueous solution both in the $a b$-plane and $c$-directions. The mean thickness of the $\mathrm{LDH}$ particles aged in the 0.6L1.6P coating for 5 weeks is $c a .4 .3 \pm 1.8 \mathrm{~nm}$ (Fig. S11c, $\mathrm{ESI} \dagger$ ), which is $c a$. 2.3-fold thicker than the freshly prepared LDH sample. Meanwhile, the mean diameter of the 5 week aged LDH particles in the $0.6 \mathrm{~L} 1.6 \mathrm{P}$ coating dispersion is $c a .218 \pm 46 \mathrm{~nm}$ (Fig. S11d, ESI $\dagger$ ), only slightly larger than the freshly prepared LDH sample of $c a .208 \pm 52 \mathrm{~nm}$. It is obvious that upon ageing, the LDH thickness growth is faster than the growth in diameter giving a smaller aspect ratio.
We have observed a similar ageing effect when using the $\mathrm{Mg}_{2} \mathrm{Al}-\mathrm{LDH} \mathrm{NS}$ that were obtained by exfoliation using a calcination and reconstruction in glycine solution method as our previously reported. ${ }^{22}$ The glycine reconstructed $\mathrm{Mg}_{2} \mathrm{Al}$ LDH NS [L(Gly)] were mixed with PVA to prepare a coating dispersion containing $3 \mathrm{wt} \% \mathrm{~L}$ (Gly) and $2 \mathrm{wt} \%$ PVA [3L(Gly)2P]. The OTR of the PET substrate freshly coated ${ }^{22}$ with the $3 \mathrm{~L}$ (Gly)2P is $1.9 \mathrm{cc} \mathrm{m}^{-2}$ day $^{-1}$. The OTR of the PET substrate (Fig. S12a, ESI $\dagger$ ) decreased to $0.4 \mathrm{cc} \mathrm{m}^{-2}$ day $^{-1}$ when the coating dispersion was aged for 6 days (6D). The OTR value further decreased to $0.1 \mathrm{cc} \mathrm{m}^{-2}$ day $^{-1}$ when the ageing time reached 6 weeks $(6 \mathrm{WK})$. A coating dispersion containing $0.6 \mathrm{wt} \%$ bentonite and $1.6 \mathrm{wt} \%$ PVA (0.6Bentonite1.6P) was also prepared. The OTR value of a $12 \mu \mathrm{m}$ PET film freshly coated with a 0.6 Bentonite1.6P dispersion was $36.6 \mathrm{cc} \mathrm{m}^{-2}$ day $^{-1}$ (Fig. S12b, ESI $\dagger$ ). The OTR value was rather stable at 38.5, 32, and $33.6 \mathrm{cc} \mathrm{m}^{-2}$ day $^{-1}$ when the 0.6Bentonite1.6P dispersion was aged for 3 days (3D), one week, and two weeks, respectively. Upon further ageing, the OTR value of the coated film decreased to $26.0,21.0$, and $18.2 \mathrm{cc} \mathrm{m}^{-2}$ day $^{-1}$ when the ageing time was 3, 4 and 6 weeks, respectively. These results suggest that the effects of ageing inorganic nanosheets in a PVA dispersion should now be studied more generally.

The aged $\mathrm{Mg}_{2} \mathrm{Al}-\mathrm{LDH}$ NS/PVA dispersion was also studied using AFM (Fig. S13, ESI $\dagger$ ). For both the formamide (Fig. S13a and $b$, ESI $\dagger$ ) and glycine (Fig. S13c and d, ESI $\dagger$ ) exfoliated $\mathrm{Mg}_{2} \mathrm{Al}-\mathrm{LDH} \mathrm{NS}$ samples the PVA polymer particles typically adopt rod or circular-like shapes with no sharp edges and attach to the $\mathrm{Mg}_{2} \mathrm{Al}-\mathrm{LDH}$ NS surface. The TEM images (Fig. S14, ESI $\dagger$ ) of the formamide (Fig. S14a, ESI $\dagger$ ) and glycine exfoliated (Fig. S14b, ESI $\dagger$ ) LDH NS and PVA dispersions clearly show PVA chains attached to the $\mathrm{Mg}_{2} \mathrm{Al}-\mathrm{LDH}$ NS surface. The $\mathrm{Mg}_{2} \mathrm{Al}-\mathrm{LDH}$ platelets grow both in diameter and in thickness while dispersed in water, which is a result of particle agglomeration and Ostwald ripening. ${ }^{28,29}$ The PVA polymer chains may act as particle growth inhibitors attaching to the surface of an $\mathrm{LDH}$ platelet. Thus, in a mixed $\mathrm{Mg}_{2} \mathrm{Al}-\mathrm{LDH}$ NS/PVA dispersion, the aspect ratio of the $\mathrm{Mg}_{2} \mathrm{Al}-\mathrm{LDH}$ NS is stable.

We further tested the oxygen transmission rate of the barrier films at $38{ }^{\circ} \mathrm{C}$ and under $50 \%$ relative humidity (Fig. S15, ESI $\dagger$ ). The uncoated $12 \mu \mathrm{m}$ PET substrate and freshly prepared 2.2 wt\% PVA coated PET substrate film show OTR values of 198.5 and $75.8 \mathrm{cc} \mathrm{m}^{-2}$ day $^{-1}$, respectively which are both higher than the same films tested at room temperature and zero relative humidity. It is a known phenomenon ${ }^{30}$ that gas permeability is usually higher when tested at a higher temperature and under a higher relative humidity. The 8 week aged $0.6 \mathrm{~L} 1.6 \mathrm{P}$ dispersion (aged at $40{ }^{\circ} \mathrm{C}$ for a week before ageing at room temperature) coated PET film has an OTR value of $3.49 \mathrm{cc} \mathrm{m}^{-2}$ day $^{-1}$, which still shows a good barrier under humidity.

\section{Hydrogen bonding}

To investigate the interactions between the PVA polymer chains and the $\mathrm{Mg}_{2} \mathrm{Al}-\mathrm{LDH}$ nanosheets, a series of ATR-IR spectroscopy experiments were carried on PET films coated with $\mathrm{Mg}_{2} \mathrm{Al}-\mathrm{LDH} \mathrm{NS} / \mathrm{PVA}$. The IR spectrum (resolution is $0.5 \mathrm{~cm}^{-1}$ ) 
of a $10 \mathrm{wt} \%$ PVA solution was used as a background control. It (Fig. 3d) showed a broad absorption centred at ca. $3328 \mathrm{~cm}^{-1}$ corresponding to the stretching vibration of hydroxyl groups due to the inter- and intra-molecular H-bonds in the PVA. ${ }^{31}$ This feature was constant and independent of the ageing time of the PVA solution. The broad band from the $6 \mathrm{wt} \% \mathrm{LDH}$ coated PET film centred at $3443 \mathrm{~cm}^{-1}$ was assigned to the $\mathrm{O}-\mathrm{H}$ stretching modes of the interlayer water molecules and of hydrogen-bonded $\mathrm{OH}$ groups from the $\mathrm{LDH}^{32}$ In contrast, we observed a gradual blue shift of the $\nu_{\mathrm{O}-\mathrm{H}}$ absorption from the 6L4P coated PET film upon ageing of the 6L4P dispersion. For example, the $\nu_{\mathrm{O}-\mathrm{H}}$ of the 6L4P coated PET film shifted from 3443 (freshly coated) to $3446,3452,3452$, and $3462 \mathrm{~cm}^{-1}$ when the $6 \mathrm{~L} 4 \mathrm{P}$ dispersion was aged for $1,2,3$, and 4 weeks, respectively. The significant blue shift suggests the hydroxyl groups within the PVA chains develop a hydrogen bonding network ${ }^{3,33,34}$ with the $\mathrm{Mg}_{2} \mathrm{Al}-\mathrm{LDH}$ nanosheet surface ${ }^{23,32}$ creating a cross-linked structure (Scheme 1). Likewise, a gradual blue shift of the $\nu_{\mathrm{O}-\mathrm{H}}$ absorption of the 1.6L0.6P coated PET film samples was observed from 3463 (freshly coated) to 3472, 3475, 3475 , and $3482 \mathrm{~cm}^{-1}$ when the 1.6L0.6P dispersion was aged for $1,3,4$, and 6 weeks, respectively, before coating (Fig. S16, ESI $\dagger$ ) whilst the $\nu_{\mathrm{O}-\mathrm{H}}$ absorption of the $2.2 \mathrm{P}$ coated PET film remains unchanged at $3340 \mathrm{~cm}^{-1}$ regardless of the ageing period of the 2.2P coating solution.

PVA adsorbed on the $\mathrm{Mg}_{2} \mathrm{Al}-\mathrm{LDH}$ nanosheet surface forming a cross-linked structure essentially increases the effective volume fraction of the LDH particles with time. PVA can dissolve in water at an elevated temperature to form hydrogen bonding between the hydroxyl groups of the polymer chains and water molecules as well as the hydroxyl groups from the $\mathrm{LDH}$ surface and the functional groups on formamide molecules. PVA aqueous solutions are metastable and their property changes with ageing time. These are due to the formation of supramolecular particles of crystalline features that have been recognised as the ageing effect. ${ }^{35,36}$ Thus, LDH particles are easier to align as ageing time increases under shear stress, which is probably related to the increased effective volume fraction. ${ }^{37}$

\section{Time-dependent long-range ordering of $\mathrm{Mg}_{2} \mathrm{Al}-\mathrm{LDH}$ NS dispersions}

Small angle X-ray scattering (SAXS) analysis of the $\mathrm{Mg}_{2} \mathrm{Al}-\mathrm{LDH}$ NS aqueous dispersions (Fig. S17, ESI $\dagger$ ) suggests some longrange ordering was upon ageing time at high $\mathrm{Mg}_{2} \mathrm{Al}-\mathrm{LDH} \mathrm{NS}$ concentrations. However, such ordering was not observed in the $\mathrm{Mg}_{2} \mathrm{Al}-\mathrm{LDH}$ NS/PVA dispersions. The SAXS curves for both a freshly prepared and an 8-month aged $6 \mathrm{wt} \%$ aqueous $\mathrm{Mg}_{2} \mathrm{Al}$ LDH NS dispersion showed that the scattering intensity $(I)$ increased consistently with $q$, indicating that the $\mathrm{Mg}_{2} \mathrm{Al}-\mathrm{LDH}$ NS are isotropically suspended. In contrast, a broad peak at $q=0.25 \mathrm{~nm}^{-1}(d=25 \mathrm{~nm})$ was observed in the SAXS data for a more concentrated $\mathrm{Mg}_{2} \mathrm{Al}-\mathrm{LDH}$ NS dispersion (10 wt $\%$ ) that had been aged for 5 months while this feature was absent in a freshly prepared dispersion suggesting that some long-range ordering of the $\mathrm{Mg}_{2} \mathrm{Al}-\mathrm{LDH}$ NS may develop upon ageing.
Moreover, first $(d=40 \mathrm{~nm})$ and second $(d=20 \mathrm{~nm})$ order broad peaks were observed in the SAXS data of a freshly prepared concentrated aqueous $\mathrm{Mg}_{2} \mathrm{Al}-\mathrm{LDH}$ NS dispersion (15 wt\%) indicating weak long-range ordering of the nanosheets exists in a concentrated suspension. ${ }^{38}$ However, the SAXS data for the 6L4P dispersion that had been freshly prepared and then aged for 10 months showed no additional scattering indicating that the $\mathrm{Mg}_{2} \mathrm{Al}-\mathrm{LDH} \mathrm{NS}$ are isotropically dispersed in the dispersion. $\mathrm{X}$-ray diffraction experiments were carried out on PET coated films to study the alignment of the $\mathrm{Mg}_{2} \mathrm{Al}-\mathrm{LDH} \mathrm{NS}$ on the surface of the substrate. PET films coated with freshly prepared, 2 day, and 4 week aged 1.6L0.6P dispersions were selected to determine the degree of alignment of the $\mathrm{Mg}_{2} \mathrm{Al}-\mathrm{LDH}$ NS in the coating layer using pole figure measurements. Powder XRD patterns of the three film samples (Fig. S18, ESI $\dagger$ ) show the same broad scattering feature centred at $c a .2 \theta=10.75^{\circ}$ corresponding to a $d$-spacing of $8.2 \AA$, which is assigned to the partial intercalation of $\mathrm{Mg}_{2} \mathrm{Al}-\mathrm{LDH}$ with PVA. $^{22}$ Pole figure measurements were made at a fixed value of $2 \theta\left(10.75^{\circ}\right)$ where each sample was scanned at a tilting angle $(\psi)$ from 0 to $40^{\circ}$ and at a rotating angle $(\varphi)$ from 0 to $360^{\circ}$ (Fig. 4a-c). The raw intensity summed from all $\varphi$ was plotted as a function of $\psi$ to estimate the full width at half maximum height (FWHM) (Fig. S19a, ESI $\dagger$ ). However, the scattering intensities from the $\mathrm{Mg}_{2} \mathrm{Al}-\mathrm{LDH}$ layers are weak compared with the scattering from the PET substrate (Fig. S19b, ESI $\dagger$ ). The fitted FWHM (Table S1, $\mathrm{ESI} \dagger$ ) values are $53.0 \pm 1.0^{\circ}, 37.3 \pm 0.8^{\circ}$, and $24.0 \pm 1.0^{\circ}$ for the PET substrate film coated with a fresh, 2 day, and 4 week aged dispersion, respectively, giving calculated degrees of the in-plane preferred orientation of the $\mathrm{Mg}_{2} \mathrm{Al}-\mathrm{LDH}$ NS parallel to the PET film of $70.6 \pm 0.6 \%, 79.3 \pm 0.5 \%$, and $86.7 \pm 0.6 \%$, respectively (Fig. 4d). The results clearly indicate that the alignment of the $\mathrm{Mg}_{2} \mathrm{Al}-\mathrm{LDH}$ NS layers in the coated film increases with ageing time.

We further characterised the viscosity of the four coating dispersion samples using rheometer. First, we measured the viscosity of two coating dispersion samples containing the same LDH and PVA weight ratio and solid content (0.6L1.6P) but aged under different conditions: one aged at $40{ }^{\circ} \mathrm{C}$ for a week then aged at room temperature (Fig. S20a, ESI $\dagger$ ) and the other aged at room temperature continuously (Fig. S20b, ESI $\dagger$ ). We observed that with time, the aged dispersion showed either a slightly higher viscosity (Fig. S20a, ESI $\dagger$ ) at the 9th week of ageing, or a similar viscosity compared with the freshly prepared dispersion (Fig. S20b, ESI $\dagger$ ). Moreover, regardless of the ageing conditions, all of the aged dispersions showed shear thinning behaviour very similar to the freshly prepared dispersion indicating that the gel did not form in the dispersion with 9 weeks of ageing time. Similarly, we measured the viscosities of two 1.6L0.6P coating dispersions: one aged at $40{ }^{\circ} \mathrm{C}$ for a week before ageing at room temperature (Fig. S20c, ESI $\dagger$ ) and the other aged at room temperature continuously (Fig. S20d, ESI $\dagger$ ). Again, regardless of the ageing conditions, all of the aged dispersions showed shear thinning behaviour and a viscosity very similar to the freshly prepared dispersion. 


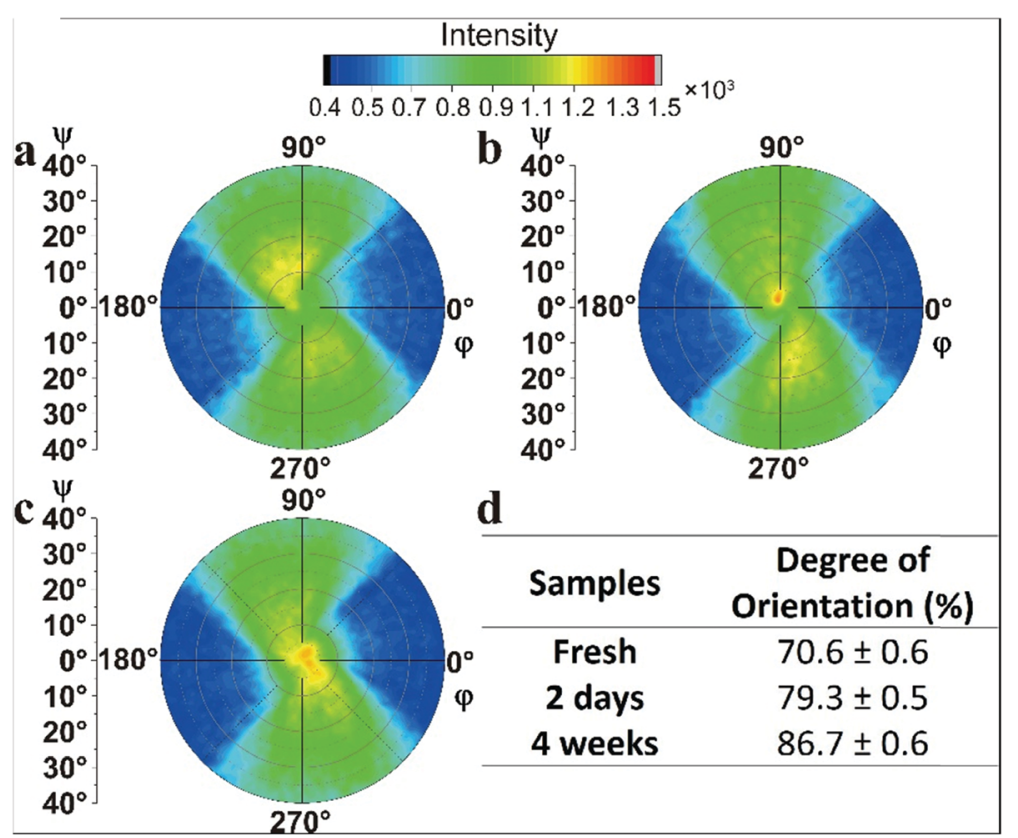

Fig. 4 Preferred orientation of the $\mathrm{Mg}_{2} \mathrm{Al}-\mathrm{LDH}$ NS as a function of ageing time. Pole figure measurements at a fixed $2 \theta\left(10.75^{\circ}\right)$ for the PET films coated with freshly prepared (a), 2 day (b), and 4 week (c) aged 1.6L0.6P dispersions (aged at $40^{\circ} \mathrm{C}$ before ageing at room temperature). Summary of the degree of preferred in-plane orientation of the $\mathrm{Mg}_{2} \mathrm{Al}-\mathrm{LDH}$ NS in the coated films (d). All the films were coated with a $6 \mu \mathrm{m}$ coating gap rod.

The surface roughness of the PET films coated with freshly prepared, 2 day, and 4 week aged 1.6L0.6P $\mathrm{Mg}_{2} \mathrm{Al}-\mathrm{LDH} \mathrm{NS} / \mathrm{PVA}$ dispersions were also analysed using AFM. Representative AFM images show that the surface roughness of the coated film decreased when the ageing time of the coating dispersion increased. The root mean square $\left(R_{\mathrm{q}}\right)$ surface roughness of the freshly coated PET substrate is $82.8 \mathrm{~nm}$ and the height range $\left(R_{z}\right)$ of the film surface is $c a .577 .0 \mathrm{~nm}$ (Fig. S21a and b, ESI $\dagger$ ). The $R_{\mathrm{q}}$ and $R_{\mathrm{z}}$ of the PET substrate decreased to 76.2 and $528.6 \mathrm{~nm}$ when the film was coated after 2 days of ageing the dispersion (Fig. S21c and b, ESI $\dagger$ ) and the values further decreased to 31.8 and $257.2 \mathrm{~nm}$ when the ageing time was increased to 4 weeks (Fig. S21e and f, ESI $\dagger$ ). The results show that using an aged coating dispersion produces a significantly smoother coating on the film, which is probably due to a more uniform dispersion and alignment of the $\mathrm{Mg}_{2} \mathrm{Al}-\mathrm{LDH} \mathrm{NS}$ in the PVA matrix.

\section{Validation of the barrier performance}

We prepared a series of coating film samples with a thicker coating layer using a coating rod with a coating gap of $24 \mu \mathrm{m}$ (compared to the previously used $6 \mu \mathrm{m}$ coating gap rod). The OTR of the PET film coated with a $2.2 \mathrm{wt} \%$ PVA dispersion with the coating rod of a larger coating gap $(24 \mu \mathrm{m})$ is $19.25 \pm$ $0.45 \mathrm{cc} \mathrm{m}^{-2}$ day $^{-1}$ (Table S2, ESI $\dagger$ ). The OTR of the PET film coated with a freshly prepared $0.6 \mathrm{~L} 1.6 \mathrm{P}$ dispersion is $4.93 \pm$ $0.65 \mathrm{cc} \mathrm{m}^{-2}$ day $^{-1}$ (Fig. 5a). However, when the same coating dispersion is stirred and aged for a week at $40{ }^{\circ} \mathrm{C}$ followed by ageing at room temperature, the OTR of the coated film significantly decreased. The OTR values of the PET film coated with the same coating dispersion aged for 4,6 , and 8 weeks are
$0.95 \pm 0.1,0.42 \pm 0.1,0.20 \pm 0.05 \mathrm{cc} \mathrm{m}^{-2}$ day $^{-1}$, respectively. This again represents a ca. 25-fold OTR decrease. The LDH position is fixed when the wet coating layer is dried. Under the same drying conditions, a thicker wet coating layer will take longer to dry, which effectively deteriorates the LDH alignment in the dried coating layer. This probably caused the smaller OTR decrease in the film series coated using the $24 \mu \mathrm{m}$ coating rod (25-fold) than the decrease observed from the film series prepared with the $6 \mu \mathrm{m}$ coating rod (37-fold) when the coating dispersion composition and ageing conditions are constant. AFM (Fig. S22, ESI $\dagger$ ) was used to measure the coating layer thickness of the barrier films. The coating layer thicknesses of the PET film coated with the 0.6L1.6P dispersion aged for 4, 6, and 8 weeks ( $24 \mu \mathrm{m}$ rod) are 435, 323, and $332 \mathrm{~nm}$, respectively (Table S2, ESI $\dagger$ ). Thus, the oxygen permeability values are $0.0245,0.0035$ and $0.0007 \times 10^{-16} \mathrm{~cm}^{3}(\mathrm{STP}) \mathrm{cm}^{-2} \mathrm{~s}^{-1} \mathrm{~Pa}^{-1}$ for the films using the fresh, 6 week and 8 week dispersion, respectively (Table S2, ESI $\dagger$ ). AFM experiments (Fig. 5b and c) were carried out to measure the surface morphology of the fresh and 8 week samples. It can be observed that the surface of the film coated with the freshly prepared (Fig. 5b) dispersion is predominantly covered with needle-like particles compared with the platelet-like particles on the surface of the film coated with the 8 week aged dispersion (Fig. 5c). This result indicates that LDH particles predominately sit on their edge (the extreme case would be perpendicular to the film surface) for the fresh sample while the particles sit on the $a b$ face (parallel to the film surface) for the 8 week sample. The same result is also observed from SEM characterisation (Fig. S23, ESI $\dagger$ ). This is a strong indication that the LDH alignment in the film coated with the 8 week aged dispersion is much better than that in the film 

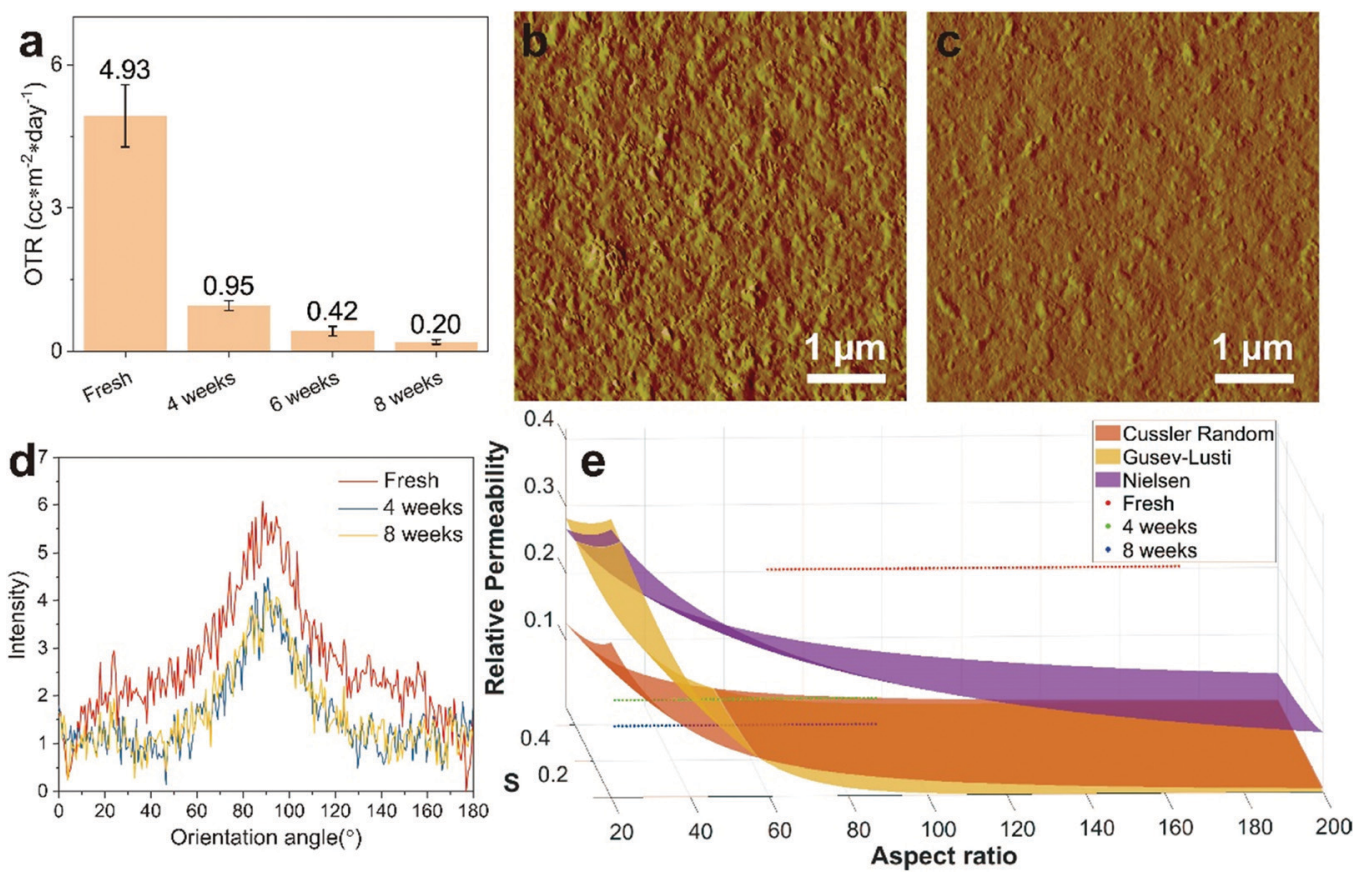

Fig. 5 Oxygen barrier property and surface of the coated films. (a) OTR of the PET substrate coated with freshly prepared, 4, 6, and 8 week aged $0.6 \mathrm{~L} 1.6 \mathrm{P}$ coating dispersions. AFM measurements of the surface of the barrier films coated with freshly prepared (b) and 8 week aged (c) $0.6 \mathrm{~L} 1.6 \mathrm{P}$ coating dispersions. (d) Azimuthally integrated diffraction intensities from the 2D XRD measurements. (e) Plot of oxygen relative permeability predicted by Dil modified theoretical models as a function of aspect ratio and $S$ compared with experimental data of the freshly coated, 4 and 8 week aged and then coated films. All the films were prepared using a coating rod with a coating gap of $24 \mu \mathrm{m}$ (the coating dispersion was first stirred and aged at $40{ }^{\circ} \mathrm{C}$ for a week before ageing at room temperature).

coated with the freshly prepared dispersion. The surface roughness values $\left(R_{\mathrm{q}}\right)$ are 9.8 and $6.8 \mathrm{~nm}$ and the $Z$ range values are 127 and $64 \mathrm{~nm}$ for the film coated with the freshly prepared and 8 week aged dispersions, respectively. The surface roughness differences contributed to the variation of the coating layer thickness between the film coated with the freshly prepared and 8 week aged dispersion.

Due to the large coating layer thickness difference, it is necessary to calculate the oxygen relative permeability of the barrier film using the permeability of a pure PVA coating film with the same coating layer thickness as the barrier film. We predicted the permeability of the pure PVA coating layer using a linear regression method. The OTR values of the PET film coated with a dispersion of pure $2.2 \mathrm{wt} \%$ PVA with coating layer thicknesses of $43(6 \mu \mathrm{m}$ rod $)$ and $210 \mathrm{~nm}(24 \mu \mathrm{m}$ rod $)$ (Fig. S24, ESI $\dagger$ ) are 31.5 and $19.25 \mathrm{cc} \mathrm{m}^{-2}$ day $^{-1}$, respectively (Table S2, ESI $\dagger$ ). The OTR value of a PVA coated film with a coating layer thickness of $890 \mathrm{~nm}$ previously reported by our group $^{22}$ was also used to do the regression (Fig. S25, ESI $\dagger$ ). The predicted permeability values of pure PVA coating layers with thicknesses of 435,323 , and $332 \mathrm{~nm}$ are $0.126,0.100$, and 0.102 , respectively (Table S2, ESI $\dagger$ ). Thus, the calculated relative permeability of the barrier coating layer is $0.2626 \pm 0.0346$, $0.0496 \pm 0.0052$, and $0.0102 \pm 0.0026$ for the PET films coated with the freshly prepared, 4 and 8 week aged $0.6 \mathrm{~L} 1.6 \mathrm{P}$ coating dispersions, respectively (Table S2, ESI $\dagger$ ).

We used a 2D XRD technique to measure the order parameter $(S)^{41,42}$ within the aged film samples (Fig. 5d).
The intensity profiles were subtracted to allow a more accurate comparison between the samples. The order parameter is $0.281,0.353$, and 0.355 for the fresh, 4 week, and 8 week aged films, respectively. This result indicates that the LDH alignment in the coating layer improves when the substrate PET film is coated with an aged dispersion.

To better understand the ageing mechanism, we modified three established models $\mathrm{s}^{40,43,44}$ that predict the relative permeability of nanoparticle filled polymer composite films with different assumed platelet size distributions and array types. We focused on the models based on particles with platelet morphology. The particle size distribution and array type of the models are briefly described in (Table S3, ESI $\dagger$ ). The three models were further modified using the $\mathrm{Dil}^{45}$ modification factor, $(1-\sqrt{(2 / 3(1-S))})$, to add order parameters to the equation (Table S3, ESI $\dagger$ ). The Dil model is a modification based on the Bharadwaj model ${ }^{39}$ that improves the prediction precision of empirical models used here. Fig. 5e shows the plot of the relative permeability as a function of particle aspect ratio and $S$. The aspect ratio ranges of $118 \pm 66$ and $62 \pm 33$ were used to plot the relative permeability of the fresh, and 4 and 8 week samples, respectively. The measured relative permeability of the fresh sample deviated from all the predicted values, which might be due to aggregation of the LDH particles (insufficient mixing). Aggregation of nanoparticles is known ${ }^{46}$ to significantly decrease the effective aspect ratio in composite films, thus the barrier layer shows a higher relative permeability than the prediction. Interestingly, the relative permeabilities of the 4 and 8 week samples fit the prediction by the 
Cussler random ${ }^{43}$ and Gusev-Lusti ${ }^{44}$ models. The results agree with the AFM measurements that the $\mathrm{LDH}$ aspect ratio has a relatively wide distribution and indicate that the $\mathrm{LDH}$ particles formed randomly spaced arrays in the coating layers.

We set the volume fraction as 0.346 and used the measured relative permeability and $S$ of the fresh, 4 week, and 8 week samples to calculate the aspect ratios predicted by the different models (Table S4, ESI $\dagger$ ). These aspect ratio values range from $25 \pm 3$ to $145 \pm 15$, which are within the range observed using AFM measurements (Fig. S1 and S11, ESI $\dagger$ ). The classic Nielsen model (Bharadwaj model is derived from this model) describes the relative permeability of composite systems filled with ribbon-like particles (mono-size distribution) of regularly spaced arrays in the polymer matrix. Previous studies ${ }^{47}$ have shown that the Nielsen model best describes systems of filler concentration in the dilute regime (typically $<10 \mathrm{vol} \%$ ), which is not the situation in our system. The Cussler random ${ }^{43}$ model attempts to address systems with mono-sized disks also in the dilute concentration regime that formed randomly spaced arrays in the polymer matrix. This model is able to predict the aspect ratio for the 4 and 8 week aged coated films, and the predicted values are within the experimentally observed ranges, but is unable to predict the aspect ratio of the fresh sample probably due to poor $\mathrm{LDH}$ dispersion in the fresh sample. The Gusev-Lusti ${ }^{44}$ model considers random arrays of disks with poly-size distribution. Thus, it has shown that the aspect ratio values predicted by the Gusev-Lusti model for all the samples fall in the experimentally observed range indicating that, similar to previous observations, ${ }^{47}$ the finite element modelling approach best fits systems containing a distribution of particles sizes. Thus, the phenomena that the oxygen transmission rate of the coating film prepared using an aged coating dispersion decreased significantly compared to a film prepared from a freshly prepared dispersion is a combined effect of improved hydrogen bonding between LDH and PVA and improved LDH particle alignment within the coating layer.

\section{Conclusions}

Ageing an aqueous coating dispersion containing $\mathrm{Mg}_{2} \mathrm{Al}-\mathrm{LDH}$ nanosheets and PVA was found to improve the oxygen barrier property of a PET substrate film due to improved alignment of the nanosheets on the dried coating layer. Hydrogen bonding was observed to form between the PVA and $\mathrm{Mg}_{2} \mathrm{Al}-\mathrm{LDH} \mathrm{NS}$ with ageing time, which promotes the formation of an interconnected ordered network.

The same ageing effect was observed in LDH NS prepared using another exfoliation agent and with a bentonite and PVA coating dispersion, suggesting this could be a general approach to improve the barrier properties of a coated substrate.

\section{Author contributions}

J. Y. conceived the idea and designed and carried out the synthesis, coating, and characterisations, analysed the data and wrote the manuscript. C. C. assisted with the SAXS experiments and discussions. J. B. G. assisted with the cross-sectional TEM and SEM, and SEM-EDX measurements. Z. W., G. M., and F. X. helped design the SAXS experiments and with data processing and discussions. J.-C. B. assisted in regulating the experiments and discussion. D. O'H. supervised the project, helped design the experiments, analysed the data and wrote the manuscript. All the authors reviewed and commented on the manuscript.

\section{Conflicts of interest}

There are no conflicts of interest to declare.

\section{Acknowledgements}

We thank SCG Chemicals Co., Ltd (Thailand) for funding (J. Y., C. C., and J.-C. B.); the Beijing Synchrotron Radiation Facility (1W2A station) and the Diamond Light Source for providing beam time at the I22 beamline (SM17095); Dr Steven Huband (University of Warwick) for the Pole figure and 2D XRD measurements and discussions and the Research Complex at Harwell for SEM, TEM and microtome instrument time. We also thank Dr Junxin Wang for useful discussions and help with Matlab.

\section{References}

1 T. Aida, E. Meijer and S. I. Stupp, Science, 2012, 335, 813-817.

2 O. C. Compton, S. W. Cranford, K. W. Putz, Z. An, L. C. Brinson, M. J. Buehler and S. T. Nguyen, ACS Nano, 2012, 6, 2008-2019.

3 P. Podsiadlo, A. K. Kaushik, E. M. Arruda, A. M. Waas, B. S. Shim, J. Xu, H. Nandivada, B. G. Pumplin, J. Lahann and A. Ramamoorthy, Science, 2007, 318, 80-83.

4 L. Nisius and S. Grzesiek, Nat. Chem., 2012, 4, 711-717.

5 M. Liu, Z. Wang, P. Liu, Z. Wang, H. Yao and X. Yao, Sci. $A d v .$, 2019, 5, eaaw5643.

6 Q. Zhang, C.-Y. Shi, D.-H. Qu, Y.-T. Long, B. L. Feringa and H. Tian, Sci. Adv., 2018, 4, eaat8192.

7 X. Hu, M. Vatankhah-Varnoosfaderani, J. Zhou, Q. Li and S. S. Sheiko, Adv. Mater., 2015, 27, 6899-6905.

8 J. Cao, C. Lu, J. Zhuang, M. Liu, X. Zhang, Y. Yu and Q. Tao, Angew. Chem., Int. Ed., 2017, 56, 8795-8800.

9 B. Wu, X. Wang, J. Yang, Z. Hua, K. Tian, R. Kou, J. Zhang, S. Ye, Y. Luo and V. S. Craig, Sci. Adv., 2016, 2, e1600579.

10 B. Mahjour, Y. Shen, W. Liu and T. Cernak, Nature, 2020, 580, 71-75.

11 S. Dai, L.-M. Funk, F. R. von Pappenheim, V. Sautner, M. Paulikat, B. Schröder, J. Uranga, R. A. Mata and K. Tittmann, Nature, 2019, 573, 609-613.

12 Y. Itoh, Y. Nakashima, S. Tsukamoto, T. Kurohara, M. Suzuki, Y. Sakae, M. Oda, Y. Okamoto and T. Suzuki, Sci. Rep., 2019, 9, 1-12.

13 F. Dollinger, F. Nehm, L. Müller-Meskamp and K. Leo, Org. Electron., 2017, 46, 242-246. 
14 E. L. Cussler, S. E. Hughes, W. J. Ward and R. Aris, J. Membr. Sci., 1988, 38, 161-174.

15 F. Ding, J. Liu, S. Zeng, Y. Xia, K. M. Wells, M.-P. Nieh and L. Sun, Sci. Adv., 2017, 3, e1701212.

16 P. Das, J.-M. Malho, K. Rahimi, F. H. Schacher, B. Wang, D. E. Demco and A. Walther, Nat. Commun., 2015, 6, 5967.

17 J. Yoo, S. B. Lee, C. K. Lee, S. W. Hwang, C. Kim, T. Fujigaya, N. Nakashima and J. K. Shim, Nanoscale, 2014, 6, 10824-10830.

18 Y. Su, V. Kravets, S. Wong, J. Waters, A. Geim and R. Nair, Nat. Commun., 2014, 5, 4843.

19 Y.-H. Yang, L. Bolling, M. A. Priolo and J. C. Grunlan, Adv. Mater., 2013, 25, 503-508.

20 Y. Dou, T. Pan, S. Xu, H. Yan, J. Han, M. Wei, D. G. Evans and X. Duan, Angew. Chem., Int. Ed., 2015, 54, 9673-9678.

21 J. Yu, K. Ruengkajorn, D.-G. Crivoi, C. Chen, J.-C. Buffet and D. O’Hare, Nat. Commun., 2019, 10, 2398.

22 J. Yu, J.-C. Buffet and D. O'Hare, ACS Appl. Mater. Interfaces, 2020, 12, 10973-10982.

23 J. Yu, B. R. Martin, A. Clearfield, Z. Luo and L. Sun, Nanoscale, 2015, 7, 9448-9451.

24 F. Cavani, F. Trifirò and A. Vaccari, Catal. Today, 1991, 11, 173-301.

25 F. Kawai and X. Hu, Appl. Microbiol. Biotechnol., 2009, 84, 227.

26 M. Wiśniewska, Colloid Polym. Sci., 2011, 289, 341-344.

27 J.-T. Zhang, R. Bhat and K. D. Jandt, Acta Biomater., 2009, 5, 488-497.

28 J. Xie, X. Zhang, H. Zhang, J. Zhang, S. Li, R. Wang, B. Pan and Y. Xie, Adv. Mater., 2017, 29, 1604765.

29 X. Pang, L. Chen, Y. Liu, M. Chi, Z. Li and J. Plank, RSC Adv., 2017, 7, 14989-14997.

30 Y. Cui, S. Kundalwal and S. Kumar, Carbon, 2016, 98, 313-333.
31 H. S. Mansur, C. M. Sadahira, A. N. Souza and A. A. Mansur, Mater. Sci. Eng., C, 2008, 28, 539-548.

32 Z. Liu, R. Ma, M. Osada, N. Iyi, Y. Ebina, K. Takada and T. Sasaki, J. Am. Chem. Soc., 2006, 128, 4872-4880.

33 P. Song, Z. Xu, Y. Lu and Q. Guo, Macromolecules, 2015, 48, 3957-3964.

34 J. H. Kim, B. R. Min, K. B. Lee, J. Won and Y. S. Kang, Chem. Commun., 2002, 2732-2733.

35 E. Gruber, B. Soehendra and J. Schurz, J. Polym. Sci.: Polym. Symp., 1974, 44, 105-117.

36 V. J. Klenin, O. V. Klenina, N. K. Kolnibolotchuk and S. Y. Frenkel, J. Polym. Sci.: Polym. Symp., 1973, 42, 931-942.

37 S. I. White, B. A. DiDonna, M. Mu, T. C. Lubensky and K. I. Winey, Phys. Rev. B: Condens. Matter Mater. Phys., 2009, 79, 024301.

38 N. Wang, S. Liu, J. Zhang, Z. Wu, J. Chen and D. Sun, Soft Matter, 2005, 1, 428-430.

39 R. K. Bharadwaj, Macromolecules, 2001, 34, 9189-9192.

40 L. E. Nielsen, J. Macromol. Sci., Chem., 1967, 1, 929-942.

41 J. Zlopasa, B. Norder, E. A. B. Koenders and S. J. Picken, Macromolecules, 2015, 48, 1204-1209.

42 R. A. Chowdhury, S. X. Peng and J. Youngblood, Cellulose, 2017, 24, 1957-1970.

43 N. K. Lape, E. E. Nuxoll and E. Cussler, J. Membr. Sci., 2004, 236, 29-37.

44 A. A. Gusev and H. R. Lusti, Adv. Mater., 2001, 13, 1641-1643.

45 E. Jalali Dil, F. Ben Dhieb and A. Ajji, Polymer, 2019, 168, 126-130.

46 E. Picard, A. Vermogen, J. F. Gérard and E. Espuche, J. Membr. Sci., 2007, 292, 133-144.

47 E. Dunkerley and D. Schmidt, Macromolecules, 2010, 43, 10536-10544. 